\title{
Analisis Torsional Rigidity dan Uji Tabrak pada Chassis Go-kart Tonykart menggunakan Finite Element Method
}

\author{
Benedictus Bayu Bagaskoro dan Julendra Bambang Ariatedja \\ Departemen Teknik Mesin, Fakultas Teknologi Industri, \\ Institut Teknologi Sepuluh Nopember (ITS) \\ e-mail: ariatedja@me.its.ac.id
}

\begin{abstract}
Abstrak-Torsional rigidity pada chassis go-kart sangatlah penting, karena go-kart dituntut lincah saat berbelok dengan ketiadaan differential gear dan sistem suspensi dalam chassis go-kart. Maka dari itu chassis harus cukup fleksibel untuk meningkatkan kemampuan berbeloknya. Selain itu, go-kart merupakan kendaraan yang terbuka untuk pengendaranya, dibutuhkan chassis yang dapat terjamin keamanan pengendaranya saat terjadi benturan. Pengujian kali ini membandingkan 2 bentuk element saja, yaitu solid element dan surface element untuk pengujian Torsional Rigidity, karena dilihat dari thickness ratio yang $<1$, geometri chassis ini cocok untuk menggunakan surface element. Pengujian ini mencoba membandingkan hasil torsional rigidity dari chassis go-kart dengan 2 bentuk elemen tersebut. Pengujian impact dilakukan untuk mengetahui keamanan chassis tersebut akibat benturan. Hasil dari simulasi kali ini berupa torsional rigidity,yan menjelaskan kekakuan gokart tersebut, lalu juga akan didapatkan bentuk dan nilai deformasi chassis tersebut dari uji impact.Hasil kekakuan dari chassis Tonykart dengan menggunakan surface element yaitu sebesar 166,17 Nm/deg untuk ukuran elemen $4,5 \mathrm{~mm}$ dan $172,47 \mathrm{Nm} / \mathrm{deg}$ untuk ukuran elemen 3,5 mm, untuk solid element sebesar 188,6 Nm/deg. Hasil ini kemudian juga dibandingkan dengan eksperimen torsional rigidity pada oleh Solazzi yang memiliki nilai kekakuan sebesar $175 \mathrm{Nm} / \mathrm{deg}$. Surface element mempunyai perbedaan terhadap eksperimen sebesar 5,1\% untuk ukuran elemen $4,5 \mathrm{~mm}$ dan $1,44 \%$ untuk ukuran elemen $3,5 \mathrm{~mm}$, sementara solid element mempunyai perbedaan sebesar $7,8 \%$. Hasil uji tabrak menyatakan bahwa chassis Tonykart ini dinilai aman dari uji tabrak depan, belakang dan samping. Bentuk dan nilai deformasi yang terjadi tidak melewati batasan deformasi yang diizinkan.
\end{abstract}

Kata Kunci-Chassis Go-kart, Deformasi, Finite Element Method, Torsional Rigidity, Uji Tabrak.

\section{PENDAHULUAN}

$S^{\prime}$ EIRING berjalannya waktu, proses perancangan suatu produk semakin canggih dan kompleks. Untuk mendapatkan hasil yang terbaik dalam proses tersebut dibutuhkan analisa-analisa teknik dari design suatu produk tersebut. Berbagai metode analisa perancangan telah dilakukan oleh manusia untuk menunjang hal tersebut, mulai dari analisa sederhana sampai dengan analisa yang kompleks menggunakan bantuan komputer. Salah satu metode yang cukup populer dan sering dilakukan dalam sebuah analisa adalah finite element method.

Terdapat berbagai metode dalam melakukan analisa menggunakan FEM. Salah satunya dengan meninjau dari bentuk elemen yang diaplikasikan pada benda uji tersebut. Terdapat 3 bentuk element yang dapat dipilih untuk proses analisa, yaitu solid element, surface element, dan beam element. Bentuk tersebut dibagi berdasarkan jumlah dimensi pada element tersebut [1]. Pada pengujian ini penulis hanya membandingkan 2 bentuk element saja, yaiu solid element dan surface element. Pada penelitian sebelumnya yang dilakukan oleh Wibisana, chassis Tonykart ini mempunyai nilai torsional rigidity sebesar 188,69 Nm/deg [2]. Penelitian itu dilakukan dengan menggunakan solid element. Eksperimen khusus untuk mendapatkan nilai torsional rigidity dari chassis go-kart juga pernah dilakukan sebelumnya oleh Solazzi, dan didapatkan nilai torsional rigidity sebesar $175 \mathrm{Nm} / \mathrm{deg}$ [3]. Nilai-nilai pada penelitian sebelumnya ini nantinya akan dijadikan acuan komparasi untuk melihat tingkat akurasi dari pengujian kali ini.

Dilihat dari bentuk geometri benda uji, yaitu chassis gokart Tonykart, memungkinkan untuk melakukan analisis menggunakan bentuk elemen surface. Hal itu dikarenakan thickness ratio dari benda uji tersebut bernilai lebih kecil dari 1.Maka dari itu penulis ingin menggunakan metode surface element pada permasalahan yang pernah diselesaikan dengan metode solid element. Surface/Shell Element ini cukup efektif untuk merepresentasikan hasil pengujian. Hal ini berpengaruh kepada waktu pengujian yang lebih singkat dari solid element. Surfacel Shell element adalah penyederhanaan secara matematis dari solid element.

Pengujian ini dilakukan dengan harapan dapat mendapatkan cara yang lebih efisien dalam melakukan analisa Finite Element Method. Dalam pengujian kali ini, fleksibilitas go-kart akan didapatkan dalam simulasi pada saat beban kendaraan berbelok dan juga dengan beban torsional. Sementara simulasi uji tabrak akan dilakukan untuk mendapatkan kekuatan chassis yang ada, dan deformasi yang terjadi pada saat terjadi tabrakan, apakah aman untuk pengemudi atau tidak.

\section{URAIAN PENELITIAN}

\section{A. Torsional Rigidity pada Chassis Go-kart}

Salah satu hal penting pada chassis adalah nilai kekakuan chassis tersebut. Besarnya nilai kekakuan ini dapat dicari dengan menggunakan torsional rigidity. Torsional rigidity dapat dihitung dengan menggunakan memberikan momen torsi pada chassis. Pada penelitian kali ini pengujian torsional rigidity disimulasikan menggunakan metode elemen hingga. Pada analisa kali ini, beban diberikan pada dua sisi yang berlawanan pada bagian tumpuan roda depan chassis yang membentuk momen kopel. Sementara pada bagian tumpuan roda belakang chassis digunakan fix support. 
Pengujian tersebut akan menghasilkan nilai torsi dan sudut punter yang mana nantinya dapat diubah menjadi nilai torsional rigidity [4].

Besarnya torsi $(\mathrm{T})$ dan sudut puntir $(\theta)$ dapat dirumuskan sebagai berikut :

$T=\left(\frac{F 1+F 2}{2}\right) \times L$

$\theta=\arcsin \left(\frac{|\delta 1|+|\delta 2|}{L}\right)$

Sehingga dapat dicari besar torsional rigidity $(\mathrm{K})$ dari chassis yang diteliti yaitu,

$K=T / \theta$

Menurut Biancolini dalam penelitiannya merekomendasikan bahwa untuk memiliki kinerja yang baik, nilai kekakuan dari chassis go-kart haruslah berkisar antara $165 \sim 169$ (N.m/deg) [5].Sehingga chassis go-kart yang nantinya akan diteliti diharapkan dapat memenuhi rekomendasi tersebut.

\section{B. Meshing}

Tabel 1 merupakan hasil uji konvergensi dari pembebanan torsional. Uji konvergensi ini dilakukan pada gaya sebesar 0,2 W. Pada uji konvergensi ini didapatkan nilai tegangan maksimal. Variabel yang berubah dari uji konvergensi ini adalah ukuran elemen. Dimana dari nilai-nilai yang didapatkan tersebut perbedaan antar variabelnya dibawah $5 \%$. Jika sudah di bawah 5\%, maka model ini dianggap konvergen. Pada tegangan maksimal dapat dilihat nilai tegangan juga berubah seiring perubahan jumlah elemen. Pada tabel uji konvergensi di atas, terlihat bahwa ukuran elemen $3.5 \mathrm{~mm}$ nilai perbedaan stress dibawah $5 \%$.

Tabel 1.

Hasil uji konvergensi dengan pengurutan ukuran elemen.

\begin{tabular}{rrrrrr}
\hline \multicolumn{1}{l}{$\begin{array}{l}\text { Ukuran } \\
\text { elemen }\end{array}$} & Node & Element & $\begin{array}{l}\text { Element } \\
\text { quality }\end{array}$ & \multicolumn{1}{l}{$\begin{array}{l}\text { Stress } \\
\text { Max }\end{array}$} & $\begin{array}{r}\text { Perbedaan } \\
\text { Stress (\%) }\end{array}$ \\
\hline $10 \mathrm{~mm}$ & 26812 & 53073 & 0.79 & 130.13 & 0 \\
$9 \mathrm{~mm}$ & 27121 & 55212 & 0.81 & 119.45 & -8.941 \\
$8 \mathrm{~mm}$ & 28929 & 57261 & 0.82 & 122.31 & 2.394 \\
$7 \mathrm{~mm}$ & 30847 & 61026 & 0.85 & 114.06 & -6.745 \\
$6 \mathrm{~mm}$ & 30547 & 60319 & 0.91 & 117.16 & 4.191 \\
$5.5 \mathrm{~mm}$ & 33976 & 67125 & 0.92 & 112.25 & -4.374 \\
$5 \mathrm{~mm}$ & 37817 & 74728 & 0.93 & 112.86 & 0.543 \\
$4.5 \mathrm{~mm}$ & 43110 & 85241 & 0.94 & 108.3 & -4.040 \\
$4 \mathrm{~mm}$ & 52725 & 104368 & 0.95 & 115.47 & 6.620 \\
$3.5 \mathrm{~mm}$ & 65163 & 129101 & 0.97 & 116.25 & 0.676 \\
$3 \mathrm{~mm}$ & 86058 & 170685 & 0.98 & 124.47 & 7.071 \\
\hline \hline
\end{tabular}

Pada pengujian kali ini diambil ukuran elemen $3.5 \mathrm{~mm}$ karena ukuran tersebut merupakan ukuran yang paling kecil perbedaan stress di bawah $5 \%$ dan juga mempunyai element quality yang paling besar, yaitu sebesar $97 \%$.

Pada pengujian kali ini juga dilakukan pengujian menggunakan ukuran elemen 4,5 mm, karena pengujian terdahulu yang dilakukan oleh Wibisana yang dijadikan acuan komparasi pengujian kali ini juga menggunakan ukuran elemen 4,5 $\mathrm{mm}$ dengan bentuk tetrahedral. Hal ini dilakukan agar dapat menghasilkan komparasi kedua elemen yang baik dengan spesifikasi elemen yang hampir sama antara keduanya.

\section{Boundary Condition Pengujian Torsional Rigidity}

Pada simulasi torsional rigidity kali ini chassis go-kart akan diberikan tumpuan berupa tumpuan tetap pada kedua bagian belakang chassis.Beban yang bekerja akan diberikan ke bagian depan sebesar F, seperti terlihat pada gambar 1 . Simulasi akan dilakukan dua kali dengan arah puntir yang berlawanan. Beban akan diberikan di bagian kanan dan kiri go-kart dengan besar yang sama tetapi arahnya berlawanan. Besarnya $F$ seperti terlihat pada tabel 2. divariasikan mulai dari 0,2 - 1,0 x berat kendaraan sendiri.

Tabel 2.

Rincian pembebanan yang diberikan..

\begin{tabular}{cc}
\hline \hline Variasi Beban & $\mathrm{F}$ \\
\hline $0,2 \mathrm{~W}$ & $254,016 \mathrm{~N}$ \\
$0,4 \mathrm{~W}$ & $508,032 \mathrm{~N}$ \\
$0,6 \mathrm{~W}$ & $762,048 \mathrm{~N}$ \\
$0,8 \mathrm{~W}$ & $1016,064 \mathrm{~N}$ \\
$1,0 \mathrm{~W}$ & $1270,080 \mathrm{~N}$ \\
\hline \hline
\end{tabular}

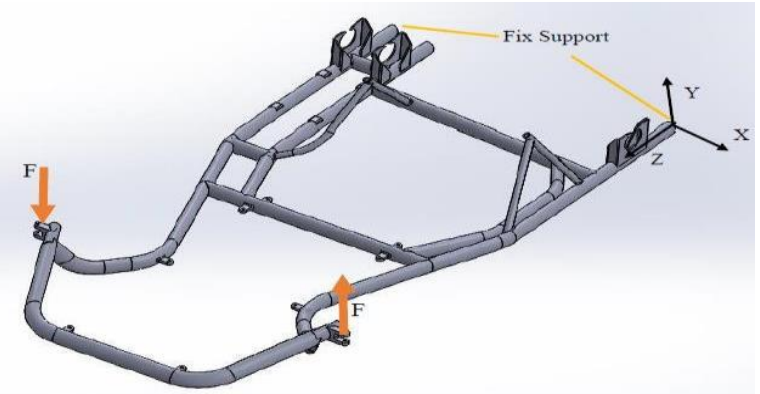

Gambar 1. Tumpuan dan pembebanan pada chassis go-kart.

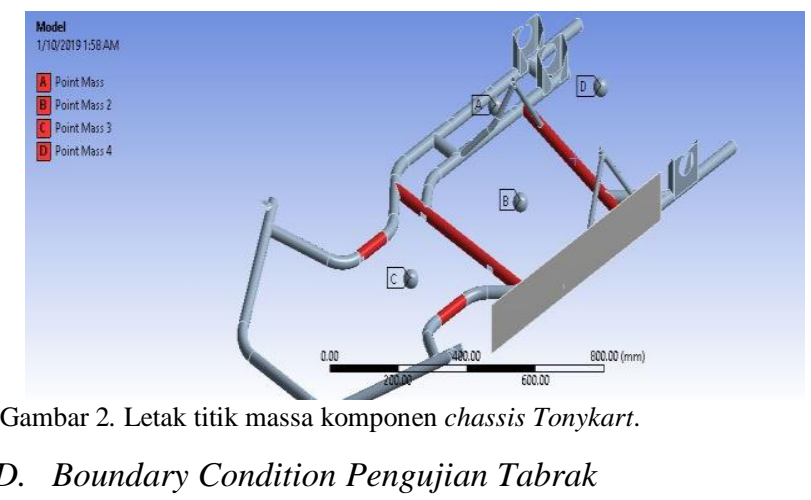

Simulasi impact kali ini akan dilakukan sebanyak 3 kali, yaitu front impact, rear impact, dan side impact. End time pada tiap simulasi dinamis kali ini diatur pada 0,05 detik dengan cycle sebanyak 300.000 cycles. Diharapkan pada saat 0,05 setelah kondisi awal go-kart sudah menabrak secara sempurna. Pada tiap simulasi impact kali ini tumpuan tetap diberikan kepada stationary rigid wall untuk uji tabrak depan dan belakang, sementara untuk uji tabrak samping, tumpuan tetap diberikan kepada chassis go-kart itu sendiri. Sementara beban kendaraan seperti mesin, pengendara, tangki, dan drivetrain juga dimasukan sesuai dengan titik berat masingmasing komponen tersebut, seperti terlihat pada gambar 2 .

Simulasi front impact ini akan meletakan tumpuan tetap (fixed support) pada stationary rigid wall di bagian depan chassis tersebut.Pada chassis go-kart diberikan pembebanan komponen-komponen sesuai dengan titik berat yang sudah di jelaskan diatas. Kemudian displacement pada go-kart diatur untuk bergerak bebas pada koordinat $\mathrm{X}$, dan $\mathrm{Z}$ saja agar gokart tidak turun atau bergerak ke arah sumbu Y. Setelah itu go-kart diberikan kecepatan sebesar $45 \mathrm{~km} / \mathrm{h}$. Kemudian dimasukan standard earth gravity sebesar $9,81 \mathrm{~m} / \mathrm{s}^{2} \mathrm{ke}$ arah sumbu Y negatif. Jarak antara chassis dan stationary rigid wall sejauh $0,5 \mathrm{~mm}$, hal ini bertujuan agar waktu end time pada simulasi tidak terlalu besar. End time yang besar akan berimbas ke durasi simulasi yang panjang. 


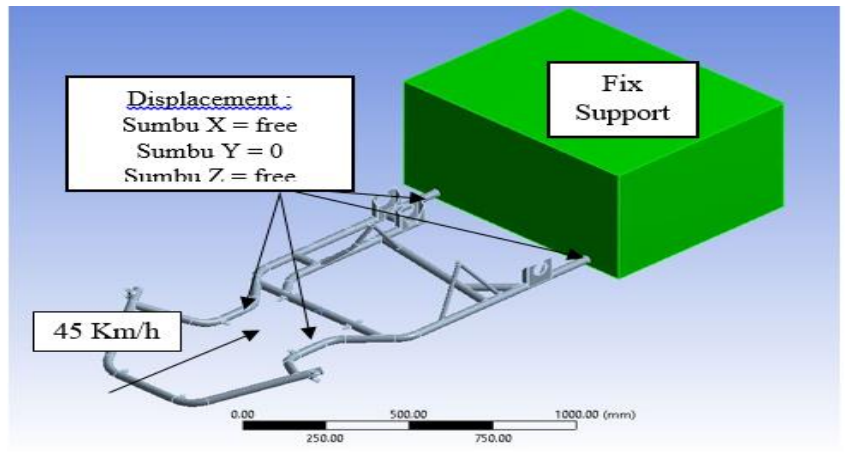

(a)

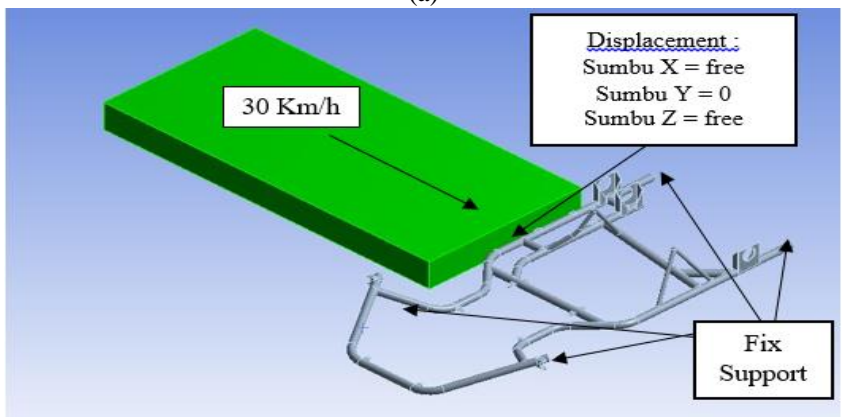

(b)

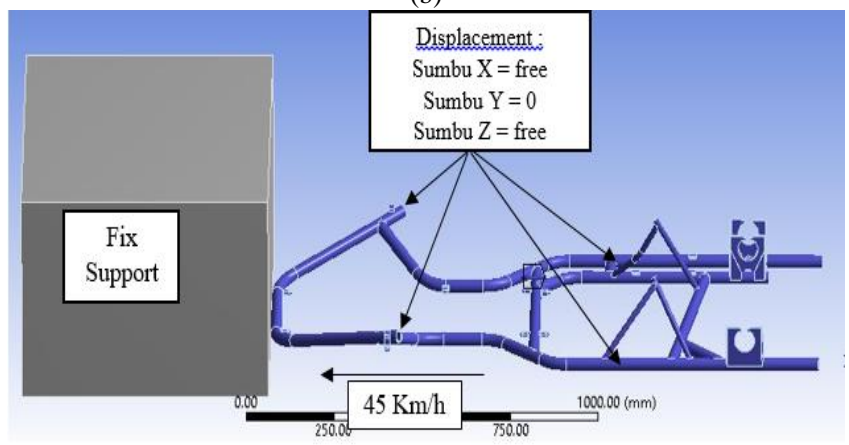

(c)

Gambar 3. Boundary condition pengujian tabrak.(a) front impact; (b) rear impact; dan (c) side impact

Simulasi front impact ini akan meletakan tumpuan tetap (fixed support) pada stationary rigid wall di bagian depan chassis tersebut.Pada chassis go-kart diberikan pembebanan komponen-komponen sesuai dengan titik berat yang sudah di jelaskan diatas. Kemudian displacement pada go-kart diatur untuk bergerak bebas pada koordinat $\mathrm{X}$, dan $\mathrm{Z}$ saja agar gokart tidak turun atau bergerak ke arah sumbu Y. Setelah itu go-kart diberikan kecepatan sebesar $45 \mathrm{~km} / \mathrm{h}$. Kemudian dimasukan standard earth gravity sebesar $9,81 \mathrm{~m} / \mathrm{s}^{2} \mathrm{ke}$ arah sumbu Y negatif. Jarak antara chassis dan stationary rigid wall sejauh $0,5 \mathrm{~mm}$, hal ini bertujuan agar waktu end time pada simulasi tidak terlalu besar. End time yang besar akan berimbas ke durasi simulasi yang panjang.

Simulasi rear impact ini memposisikan stationary rigid wall sebagai fixed support pada bagian belakang chassis. Pada chassis go-kart diberikan pembebanan komponenkomponen sesuai dengan titik berat yang sudah di jelaskan diatas. Kemudian displacement pada gokart diatur untuk bergerak bebas pada koordinat $\mathrm{X}$, dan $\mathrm{Z}$ saja. Kemudian dimasukan standard earth gravity sebesar $9,81 \mathrm{~m} / \mathrm{s}^{2} \mathrm{ke}$ arah sumbu Y negatif. Setelah itu go-kart diberikan kecepatan sebesar $45 \mathrm{~km} / \mathrm{h}$ bergerak kearah sumbu $\mathrm{Z}$ negatif.

Pada kondisi tabrak samping, gokart disimulasikan mendapat impact dari eksternal. Maka dari itu fix support diletakan pada tumpuan ke 4 sisi go-kart. Lalu benda uji diberikan kecepatan sebesar $30 \mathrm{~km} / \mathrm{h}$, dengan displacement bebas pada sudut $\mathrm{X}, \mathrm{Z}$ saja. Material benda uji disamakan dengan material chassis go-kart, yaitu chromemolly. Standard earth gravity diberikan sebesar 9,81 m/s2 ke arah sumbu Y negatif.

\section{HASIL DAN PEMBAHASAN}

\section{A. Komparasi Hasil Pengujian Solid Element dan Surface Element}

Hasil pengujian ini kemudian dibandingkan dengan hasil pengujian Wibisana pada tahun 2018 yang menggunakan bentuk elemen solid pada pengujian torsional rigidity. Tujuan pengujian ini adalah mencari tahu perbedaan penggunaan elemen solid dan surface dalam pengujian torsional rigidity pada chassis Tony Kart ini. Pada torsi puntir dengan besar sama-sama 197,44 Nm, hasil sudut puntir yang didapatkan oleh elemen solid adalah 1,05 deg, hasil tersebut lebih kecil daripada sudut puntir yang didapatkan oleh elemen surface yaitu sebesar 1,19 deg. Saat torsi puntir sebesar 987,21 Nm pun hasil yang didapatkan juga mengatakan bahwa elemen surface memiliki nilai yang lebih besar daripada elemen solid, yaitu 5,95 deg, sementara elemen solid 5,24 deg.

Sementara itu perbedaan hasil deformasi terhadap sudut $Y$ dapat dilihat dari grafik pada gambar 4 (b). Terlihat dari grafik tersebut hasil deformasi terhadap sudut $\mathrm{Y}$ pada elemen solid sebesar $7.26 \mathrm{~mm}$ pada saat diberikan gaya paling kecil yaitu $246,8 \mathrm{~N}$, sementara untuk elemen surface didapatkan nilai $8,19 \mathrm{~mm}$. Sementara pada saat gaya yang diberikan sebesar 1234,02 N, hasil deformasi yang terjadi pada elemen solid menunjukan angka yang lebih kecil juga seperti grafikgrafik lainnya, yaitu sebesar $36,28 \mathrm{~mm}$ sementara untuk surface elemen hasil yang didapatkan adalah sebesar 41,91 mm.

Hal ini menyebabkan hasil torsional rigidity kedua bentuk elemen tersebut terdapat perbedaan. Pada elemen solid

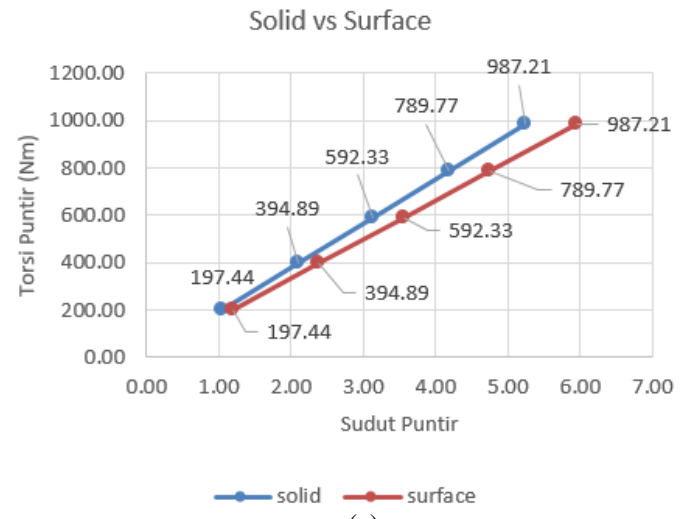

(a)

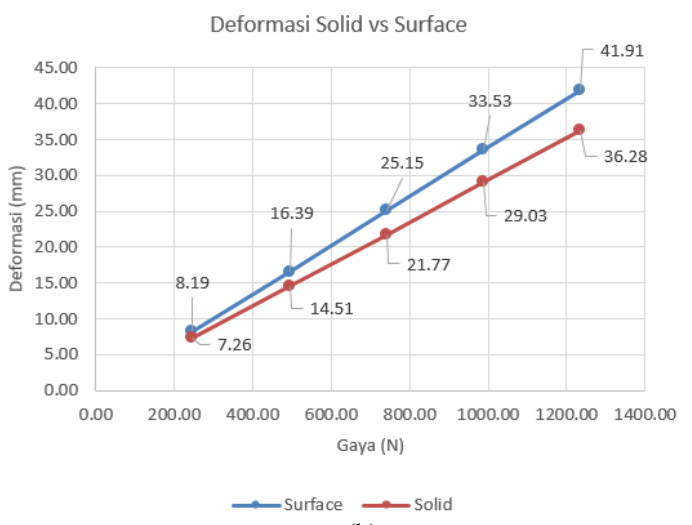

(b)

Gambar 4. Grafik pengujian solid vs surface. (a) Torsi puntir terhadap sudut puntir; dan (b) Deformasi terhadap gaya. 
didapatkan kekakuan chassis go-kart sebesar 188,6 Nm/deg sementara pada elemen surface kekakuan yang didapatkan adalah $166.17 \mathrm{Nm} / \mathrm{deg}$.

Tabel 3. menjelaskan perbedaan penggunaan bentuk elemen pada pengujian kali ini. Kedua bentuk elemen menggunakan jenis elemen yang sama pula yaitu berbasis triangle, dengan ukuran elemen yang sama yaitu $4,5 \mathrm{~mm}$. Terlihat jelas bahwa elemen solid mempunyai jumlah elemen yang jauh lebih banyak daripada elemen surface. Penggunaan elemen solid mempunyai 464.359 elemen, sementara penggunaan elemen surface mempunyai 85.241. Hampir 5 kali lipat perbedaan jumlah elemen yang ada.

Tabel 3.

Tabel perbandingan elemen pada pengujian torsional rigidity.

\begin{tabular}{cccc}
\hline \hline $\begin{array}{c}\text { Bentuk } \\
\text { Element }\end{array}$ & $\begin{array}{c}\text { Jumlah } \\
\text { Node }\end{array}$ & $\begin{array}{c}\text { Jumlah } \\
\text { Elemen }\end{array}$ & $\begin{array}{c}\text { Element } \\
\text { Quality }\end{array}$ \\
\hline Surface-Tetra & 43110 & 85241 & 0.943 \\
Solid-Tetra & 838738 & 464359 & 0.735 \\
\hline \hline
\end{tabular}

Tabel 4.

Tabel perbandingan waktu.

\begin{tabular}{|c|c|c|c|c|c|c|c|}
\hline & $\begin{array}{l}\text { Pre- } \\
\text { Processi } \\
\text { ng Time } \\
\text { (s) }\end{array}$ & $\begin{array}{l}\text { Proses } \\
\text { (s) }\end{array}$ & Meshing & $\begin{array}{l}\text { Waktu } \\
\text { (s) }\end{array}$ & Simulasi & $\begin{array}{l}\text { Total } \\
\text { (s) }\end{array}$ & Waktu \\
\hline Surface & 189 & & 15 & & 25 & & 229 \\
\hline Solid & 0 & & 58 & & 439.2 & & 497.2 \\
\hline
\end{tabular}

Jumlah elemen yang banyak tersebut kemudian berdampak kepada jumlah node yang lebih banyak pula pada elemen solid, yaitu sebanyak 838.738 dibanding jumlah elemen pada surface yaitu sebanyak 43.110 node. Selain itu element quality juga berpengaruh terhadap perbedaan yang terjadi. Dilihat dari table di atas, kualitas elemen surface lebih besar daripada elemen solid. Elemen surface mempunyai kualitas elemen 94\%, sementara solid mempunyai kualitas elemen $73,5 \%$. Dalam pengujian kali ini, seharusnya elemen surface memiliki hasil yang lebih mendekati aslinya daripada elemen solid. Hal itu terjadi karena elemen surface mempunyai kualitas elemen yang hampir mendekati $100 \%$, atau berarti proses meshing elemen surface tersebut hampir mendekati sempurna.

Dari tabel 4. terlihat bahwa penggunaan elemen surface menghemat waktu yang sangat banyak. Dari waktu sebelum melakukan simulasi, surface element memakan waktu 189 detik. Waktu ini digunakan untuk proses perubahan geometri solid atau geometri aslinya menjadi geometri surface. Proses ini berlangsung di software DesignModeler. Sementara tidak terdapat pre-processing dalam solid elemen, karena penggunaan solid elemen dapat langsung diaplikasikan pada model. Dilihat dari proses meshing, terlihat surface element memakan waktu 15 detik sementara untuk elemen solid memakan waktu sebanyak 58 detik. Hal ini dikarenakan jumlah node dan elemen pada elemen solid lebih banyak secara signifikan daripada elemen surface. Elemen solid menyelesaikan simulasi dengan waktu 439.2 detik, atau 7 menit dan 19 detik. Sementara untuk elemen surface waktu yang dijalankan jauh lebih sedikit, yaitu 25 detik. Total waktu pengerjaan pada elemen solid pada satu variasi pengujian ini adalah 497,2 detik, atau sekitar hampir 8 menit. Sementara untuk elemen surface 229 detik atau sekitar 3 menit dan 49 detik. Untuk pengujian kali ini terdapat 5 variasi pembebanan. Total waktu untuk pengujian kali ini dengan 5 variasi pembebanan untuk elemen solid adalah 2.486 detik atau sekitar 41 menit dan 26 detik, sementara untuk elemen surface selama 1.145 atau sekitar 19 menit dan 5 detik. Dari total alokasi waktu ini, terlihat bahwa elemen surface bisa menghemat waktu sebesar sekitar 22 menit dalam pengujian kali ini tanpa harus mengorbankan banyak pada akurasinya.

\section{B. Hasil Pengujian dengan Surface Element}

Pengujian torsional rigidity ini juga dilakukan dengan ukuran elemen $3.5 \mathrm{~mm}$. Ukuran elemen tersebut didapatkan dari uji konvergensi yang telah dilakukan sebelumnya. Berbeda dengan pengujian sebelumnya yang menggunakan ukuran elemen 4,5 mm yang bertujuan untuk membandingkan langsung dengan hasil yang didapatkan oleh solid elemen dengan spesifikasi elemen yang hampir sama. Pengujian ini bertujuan untuk mengkomparasi hasil penggunaan surface element dengan eksperimen Solazzi yang sudah ada.

\section{Gaya vs Deformasi}

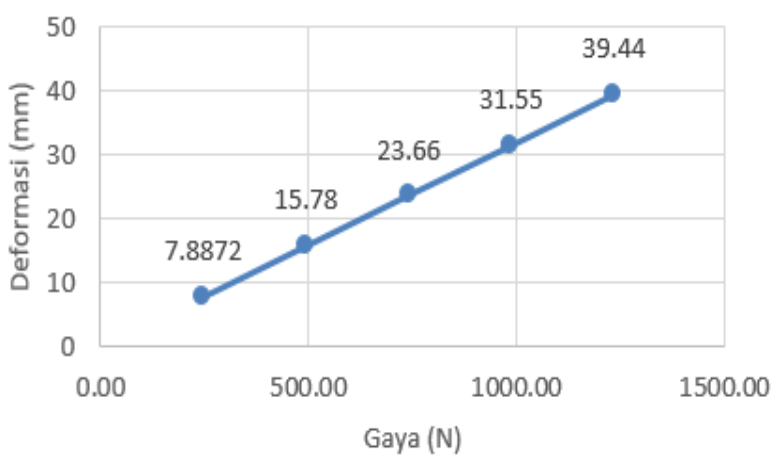

Gambar 5. Grafik gaya terhadap deformasi dengan ukuran elemen 3,5 mm.

Pada gambar 5. terlihat ketika gaya yang diberikan sebesar $246,80 \mathrm{~N}$, deformasi yang terjadi sebesar 7,8872 $\mathrm{mm}$, sementara ketika gaya yang diberikan semakin besar, seperti 1234,02 N, deformasi yang terjadi sebesar 39,44 mm. Dapat disimpulkan juga gaya yang diberikan berbanding lurus terhadap deformasi yang terjadi terhadap sumbu Y.

Letak deformasi $\mathrm{Y}$ maksimum dan minimum dari gaya yang diberikan terjadi pada tumpuan roda depan kanan dan kiri. Hasil kekakuan chassis Tony Kart dengan ukuran elemen 3,5 mm mendapatkan hasil torsional rigidity sebesar $172,47 \mathrm{Nm} / \mathrm{deg}$. Jika dibandingkan dengan eksperimen Solazzi, perbedaan nilai yang didapatkan sebesar $1,44 \%$. Nilai perbedaan tersebut lebih kecil jika dibandingkan dengan pengujian sebelumnya yang dilakukan dengan surface element maupun solid element dengan ukuran elemen 4,5 $\mathrm{mm}$. Sementara nilai perbedaan dengan ukuran $4,5 \mathrm{~mm}$ adalah sebesar $3,77 \%$.

Pada pengujian dengan menggunakan ukuran elemen 3.5 $\mathrm{mm}$, juga dicatat waktu yang dibutuhkan dalam proses analisisnya. Proses meshing pada ukuran elemen $3.5 \mathrm{~mm}$ ini berlangsung selama 18 detik, hal ini lebih memakan waktu dari penggunaan elemen 4,5 mm karena jumlah elemen dan jumlah node yang lebih banyak pada ukuran elemen 3,5 mm. Hal itu berdampak ke waktu total pengerjaan untuk satu kali variasi simulasi sebesar 246 detik atau sekitar 4 menit dan 6 detik. Terdapat 5 variasi dalam satu kali pengujian. Waktu total untuk satu kali pengujian torsional rigidity dengan penggunaan elemen $3,5 \mathrm{~mm}$ adalah 1.230 detik, atau sekitar 20 menit dan 30 detik, dimana lebih memakan waktu hanya sekitar 1 menit dan 15 detik dari pengunaan ukuran elemen $4,5 \mathrm{~mm}$. 
Tabel 5.

Tabel waktu simulasi dengan ukuran elemen 3,5 mm.

\begin{tabular}{llllll}
\hline \hline & $\begin{array}{l}\text { Pre-Processing } \\
\text { Time (s) }\end{array}$ & $\begin{array}{l}\text { Proses } \\
\text { Meshing (s) }\end{array}$ & $\begin{array}{l}\text { Waktu } \\
\text { Simulasi (s) }\end{array}$ & $\begin{array}{l}\text { Total } \\
\text { Waktu (s) }\end{array}$ \\
\hline $\begin{array}{l}\text { Surface } \\
\mathbf{( 3 , 5} \mathbf{~ m m})\end{array}$ & & 189 & 18 & 39 & 246 \\
\hline
\end{tabular}

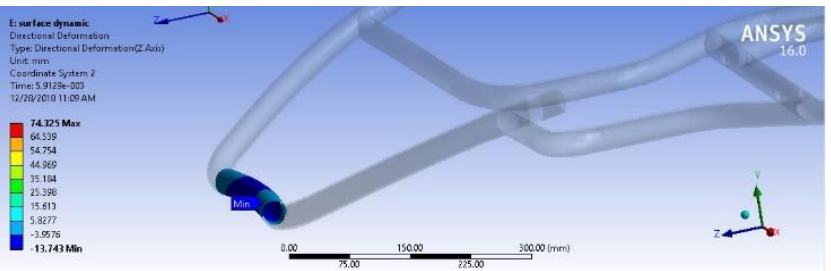

Gambar 6. Bentuk deformasi dari front impact.

\section{Hasil Pengujian Impact}

Nilai deformasi maksimal dari chassis go-kart ini setelah diuji tabrak depan adalah $13.743 \mathrm{~mm}$. Artinya adalah, bagian paling depan dari chassis go-kart tersebut, mengalami deformasi terhadap sumbu $\mathrm{Z}$ sebesar $13.743 \mathrm{~mm}$ ke arah belakang. Dimana angka ini terbilang masih aman, karena batas maksimal deformasi yang diizinkan pada chassis gokart ini adalah $30 \mathrm{~mm}$. Posisi pedal gas dan rem, dimana tempat bersandarnya kaki pengendara berada di jarak $30 \mathrm{~mm}$ dari bagian paling depan go-kart tersebut. Hasil menunjukan bahwa bentuk deformasi ketika terjadi tabrakan dari sisi depan dengan kecepatan maksimal $45 \mathrm{~km} / \mathrm{h}$ masih bisa dikatakan aman atau tidak melukai pengemudinya. Bentuk deformasinya dapat dilihat pada gambar 6.

Dari hasil tabrak belakang tersebut, didapatkan nilai deformasi maksimal yang masih tergolong aman, yaitu hanya $12.596 \mathrm{~mm}$ saja. Sementara batas nilai deformasi maksimal dari bagian paling luar chassis tersebut adalah $30 \mathrm{~mm}$. Titik aman deformasi hanya dilihat dari bagian paling belakang gokart saja karena bertujuan untuk melihat bentuk dan nilai pergeseran komponen di daerah tersebut. Apakah pergeserannya dapat melukai pengendara atau tidak. Ternyata dari simulasi yang sudah dilakukan, nilai dan bentuk deformasi terebut terbilang masih aman untuk bagian belakang chassis go-kart. Pergeseran komponen yang terjadi pun tidak dapat melukai pengemudinya. Dilihat dari bentuk deformasinya pada gambar 7 , terlihat tidak mengalami banyak perubahan jika dibandingkan dengan bentuk pada saat sebelum dilakukannya pengujian. Hal ini kemungkinan disebabkan karena bentuk frame bagian belakang yang kokoh dan juga bentuk dari frame bagian belakang yang searah dengan arah gaya yang didapat. Sehingga bentuk dan nilai deformasinya tidak membahayakan bagi pengemudinya.

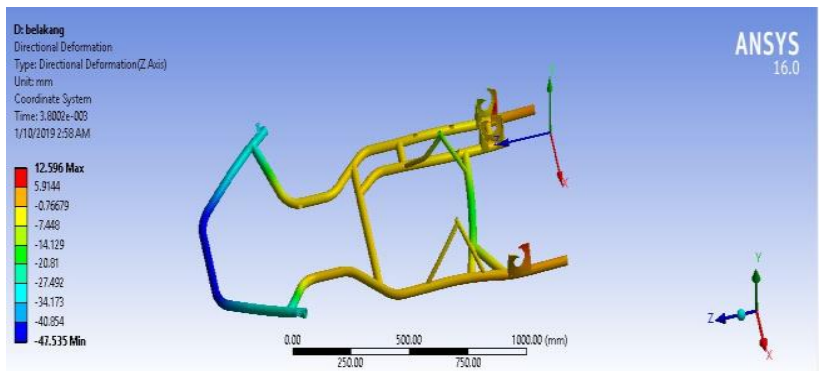

Gambar 7. Bentuk deformasi dari rear impact.

Nilai deformasi pada uji tabrak samping kanan yang didapat dari simulasi sebesar $18,33 \mathrm{~mm}$ dan nilai deformasi untuk uji tabrak samping kiri sebesar 27,6 mm. Lalu bentuk deformasi seperti terlihat pada gambar 8 (a) dan (b).
Deformasi maksimal terdapat pada area dudukan mesin gokart tersebut. Hasil tersebut dikategorikan masih aman karena tidak melewati batas deformasi sebesar $30 \mathrm{~mm}$.

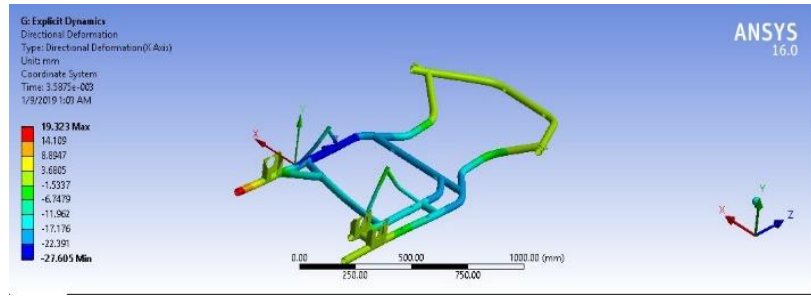

(a)

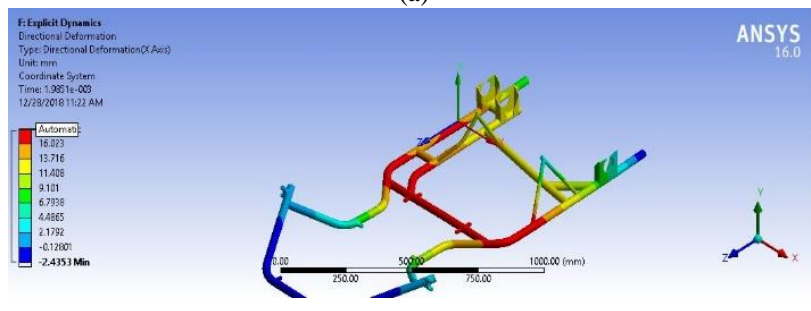

(b)

Gambar 8. Bentuk deformasi uji tabrak samping. (a) kanan; (b) kiri.

Bentuk dan nilai deformasi yang dihasilkan tidak akan berdampak pada pengendara go-kart. Dampak terbesar pada uji tabrak samping ini ada kepada mesin go-kart yang berada di daerah deformasi maksimal tersebut.

\section{KESIMPULAN}

Kesimpulan dari pengujian ini adalah sebagai berikut :

1) Penggunaan surface element dengan bentuk elemen triangle ukuran elemen $4,5 \mathrm{~mm}$ dalam pengujian torsional rigidity pada chassis go-kart Tonykart kali ini mendapatkan hasil kekakuan sebesar 166,17 Nm/deg. Sementara pengujian yang sama dilakukan dengan solid element mendapatkan hasil kekakuan sebesar 188.61 $\mathrm{Nm} / \mathrm{deg}$. Lalu dengan beban maksimal yang diberikan yaitu sebesar 1234,02 N, surface element mendapatkan deformasi terhadap sumbu Y sebesar 41,91 mm. Sementara solid element mendapatkan hasil sebesar $36,28 \mathrm{~mm}$.

2) Pengujian dengan surface dan solid element kemudian dibandingkan dengan hasil eksperimen yang dilakukan oleh Solazzi dengan menggunakan chassis go-kart yang sama yaitu Tonykart. Hasil dari eksperimen Solazzi mendapatkan nilai kekakuan go-kart sebesar 175 $\mathrm{Nm} / \mathrm{deg}$. Hasil tersebut kemudian dibandingkan dengan simulasi menggunakan surface dan solid element. Terdapat perbedaan sebesar 5,1\% dengan hasil yang didapat dengan menggunakan surface element dengan ukuran 4,5 mm dan 1,44\% dengan ukuran elemen 3,5 $\mathrm{mm}$. Sementara terdapat perbedaan $7,8 \%$ dengan hasil yang didapat dengan menggunakan solid element. Hal ini menyatakan bahwa hasil yang didapat dari penggunaan surface element dapat mendekati dari hasil pada kondisi eksperimen. Ini menunjukan bahwa penggunaan surface element dapat digunakan pada permasalahan statis semacam ini, dimana sesuai dengan syarat penggunaan surface element yaitu, rasio ketebalan dari geometri yang diuji kurang dari 1.

3) Didapatkan deformasi sebesar $13,743 \mathrm{~mm}$ pada uji tabrak depan dengan kecepatan maksimal go-kart sebesar $45 \mathrm{~km} / \mathrm{h}$. Besar deformasi tersebut dinilai aman karena masih dibawah batasan nilai deformasi sebesar 30 $\mathrm{mm}$. Setelah itu dari uji tabrak belakang, dengan 
kecepatan maksimal go-kart sebesar $45 \mathrm{~km} / \mathrm{h}$, didapatkan nilai deformasi sebesar $12,59 \mathrm{~mm}$. Hasil ini terbilang aman karena masih dibawah batasan nilai deformasi. Lalu untuk uji tabrak samping, dengan go-kart ditabrak oleh benda dengan kecepatan $30 \mathrm{~km} / \mathrm{h}$. Hasil deformasi sebesar $18.33 \mathrm{~mm}$ dan $27.6 \mathrm{~mm}$. Hasil tersebut dikategorikan masih aman karena tidak melewati batas deformasi sebesar $30 \mathrm{~mm}$. Setelah melakukan uji tabrak, dapat disimpulkan chassis go-kart Tonykart terbilang aman dari tabrakan segala sisi dan deformasi yang terjadi tidak dapat membahayakan atau melukai pengendaranya.

\section{DAFTAR PUSTAKA}

[1] N. S. Gokhale, S. V Bedekar, and A. N. T. S. Deshpande S., Practical finite element analysis. Finite To Infinite, 2008.

[2] Y. D. S. Wibisana, "Analisis torsional rigidity, efek jacking, dan kekuatan chassis go-kart akibat beban belok," ITS Surabaya, 2018

[3] S. Solazzi and M. Matteazzi, Analisi e sviluppi strutturali di un telaio per kart da competizione. Parma: AIAS, 2002

[4] M. Zaqqi, "Simulasi kekuatan dan torsional rigidity chassis sapuangin speed 3," ITS Surabaya, 2015.

[5] M. E. Biancolini, B. Riccardo, and R. Luigi, "Integrated multi body/FEM analysis of vehicle dynamic behaviour," University Tor Vergata, 2002. 